\title{
ĐÁNH GIÁ HIẾU QUẢ HOÁ XẠ TRI ĐỒNG THỜI TRIỆT CĂN UNG THƯ THỰC QUẢN GIAI ĐOẠN III SỬ DỤNG PHÁC ĐỒ PC HÀNG TUẦ
}

\author{
Phạm Đình Phúc ${ }^{1}$, La Vân Trường ${ }^{2}$, \\ Nguyễn Văn Ba ${ }^{1}$, Trần Đình Thiết ${ }^{1}$
}

\section{TÓM TẮT}

Mục tiêu: Đánh giá hiệu quả hoá xạ trịđồng thời triệt cắn (HXTĐTTC) trong điêu trị (ĐT) ung thư thực quản (UTTQ) giai đoạn III đồng thời nhận xét một số tác dung không mong muốn (TDKMM) của phương pháp ĐT này. Đối tượng và phương pháp: Nghiên cứu mô tả hồi cứu kết hợp tiến cưuutrên 42 bệnh nhân (BN) được xa trị IMRT hoặc 3D - CRT (liều 50,4 Gy cho vùng thể tích dự phòng, $60-66$ Gy cho vùng u và hạch nguyên phát) kết hợp hóa chất Paclitaxel Carboplatin (PC) hàng tuần (liều Paclitaxel $50 \mathrm{mg} / \mathrm{m}^{2}$, Carboplatin AUC 2pha truyền tĩnh mạch ngày 1 , chu kỳ 7 ngày trong quá trình xa trị), đánh giá kết quả điêu trị trên lâm sàng, trên cắt lớp vi tính (CLVT) theo RECIST và tác dụng không mong muốn sau 4 tuần kể từ khi kết thúc điều trị. Kết quả: Tỷ lệ đáp ứng sau điều trị trên lâm sàng đạt 90,5\%. Tỷ lệ đáp ứng khách quan đat $85,7 \%$, trong đó đáp ứng hoàn toàn đạt tỷ lệ $33,3 \%$ và không có $B N$ tiến triển sau điều trị trong thời gian theo dõi, đánh giá. Qua phân tích một số yếu tố liên quan đến đáp ứng điều trị bao gồm: giai đoạn $T$ ( $T_{2}$ đáp ứng tốt hơn $T_{3}, p=0,023$ ), giai đoạn $\mathrm{N}$ ( $\mathrm{N}_{1}$ đáp ứng tốt hơn $\left.\mathrm{N}_{2}, \mathrm{p}=0,001\right)$, kích thước $\mathrm{u}$ (kích thước u nhỏ đáp ứng tốt hơn kích thước u lớn, $p$ $=0,033$ ), kỹ thuật xạ trị (xa trị bằng kỹ thuật IMRT cho hiệu quả tốt hơn kỹ thuật 3D - CRT, $p=0,006$ ). TDKMM sớm hay gặp liên quan đến xạ trị bao gồm viêm da $(61,9 \%)$, viêm thực quản $(38,1 \%)$ và viêm phổi $(11,9 \%)$ độ 1 , độ 2 . Hầu hết các TDKMM trên hệ huyết học, tiêu hoá, gan thận ở độ 1 và 2 ; chỉ gặp 2,4\% bệnh nhân giảm bạch câu độ 3 . Kết luận: HXTĐTTC với phác đồ PC hàng tuần điều trị BN UTTQ giai đoạn III đảm bảo tốt kế hoạch điều trị, TDKMM chấp nhận được và hiệu quả điều trị tương đương với phác đồ CF.

Tư khóa: Hóa xa trị đồng thời triệt căn, ung thư thực quản giai đoạn IIII.

\section{SUMMARY}

\section{EVALUATING THE TREATMENT OUTCOMES OF DEFINITIVE CONCURRENT CHEMORADIOTHERAPY (dCRT) FOR PATIENTS WITH STAGE III ESOPHAGEAL CANCER (EC)}

Objective: To evaluatethe treatment outcomes of definitive concurrent chemoradiotherapy (dCRT) for patients with stage III esophageal cancer (EC) and

\footnotetext{
*Bệnh viện Quân y 103

**Bệnh viện TUQQĐ108

Chịu trách nhiệm chính: Nguyễn Văn Ba

Email: bsnguyenvanba@yahoo.com

Ngay nhận bài: 16/3/2021

Ngày phản biện: 10/4/2021

Ngày duyệt bài: 7/5/2021
}

comment on several side effects of the treatment. Subject and methods: A descriptive retrospective combined prospective study on42 patients with stage III esophageal cancerreceiving IMRT or 3D - CRT radiation therapy (dose are typically 50.4 Gy forprophylactic radiotherapy and around $60-66$ Gy of radiotherapy for primary tumor and lymph node regions) in combination with weekly $P C$ regimen(the Paclitaxel dose was $50 \mathrm{mg} / \mathrm{m}^{2}$ in combination with Carboplatin administered the dose at AUC2 on day 1 of weekly cyclesduring radiotherapy period).Evaluationof the treatment outcomesand the side effects is performed 4weeks after the completionof dCRT that based on clinial examination and CT imaging according to RECIST 1.1. Results: The overall clinical response rate after treatment reached $90.5 \%$. The overall objective response rate according to RECIST 1.1 was $85.7 \%$ with $33.3 \%$ of the patients achieving complete response. There was no progression after treatment during follow - up and evaluation. Several factors related to the treatment outcomes include $T$ stage (stage $T_{2}$ response was significantly better than stage $T_{3}, p=0.023$ ), $N$ stage (stage $\mathrm{N}_{1}$ response was significantly better than stage $\mathrm{N}_{2}, \mathrm{p}=0.001$ ), tumor size (the response of small tumors is significantly better than of large ones, $p=$ 0.033 ), radiotherapy techniques (IMRT is significantly better than $3 D-C R T, p=0.006)$. The most common major radiotherapy - induced side effects were dermatitis $(61.9 \%)$, esophagitis $(38.1 \%)$, pneumonitis $(11.9 \%)$. Most of common major hematologic and nonhematologic toxic effects were at grade 1 and 2 . Just $2.4 \%$ of the patients suffered from severe neutropenia (grade 3 ). Conclusion: dCRT with weekly PC regimen is the effective, safe and less toxicity treatment for patients with unresectable stage III esophageal cancer.

Keywords: Definitive concurrent chemoradiotherapy, stage III esophageal cancer.

\section{I. ĐĂT VẤN ĐỀ}

Ung thư thực quản (UTTQ) là loại ung thư phổ biến đứng thứ 9 trong tổng số các loại ung thư và đứng thứ 3 trong ung thư đường tiêu hoá sau ung thư đại trực tràng và ung thư dạ dày. Theo GLOBOCAN, năm 2020 tại Việt Nam, bệnh đứng thứ 14 trong các bệnh ung thư với 3.281 ca mắc mới, tuy nhiên lại đứng thứ 9 về tỷ lệ tử vong với 3.080 ca chiếm 2,5\% [1]. Đối với bệnh nhân UTTQ giai đoạn III, khi không có chỉ định phẫu thuật thì HXTĐTTC là giải pháp hàng đâu trong mục tiêu điều trị khỏi bệnh. Có nhiêuu phác đồ hoá chất có thể lựa chọn trong HXTĐTTC UTTQ, phác đồ CF được sử dụng thường xuyên. 
Một số nghiên cứu gần đây cho thấy, phác đồ PC hàng tuần trong HXTĐTTC UTTQ cho hiệu quả về thời gian sống bệnh không tiến triển (PFS) và thời gian sống còn toàn bộ (OS) tương đương nhưng lại có tỷ lệ TDKMM thấp hơn và mức độ tuân thủ điều trị của bệnh nhân cao hơn khi dùng phác đồ $\mathrm{CF}$. Ở Việt Nam, hiện có rất ít nghiên cứu về hiệu quả của phương pháp điều trị này. Vì vậy, chúng tôi tiến hành thực hiện đề tài: "Đánh giá hiệu quả hoá xạ trị đồng thời triệt căn ung thư thực quản giai đoạn III sử dụng phác đồ PC hàng tuần", với 2 mục tiêu: 1) Đánh giá hiệu quả hoá xạ trị đồng thời triệt căn ở bệnh nhân ung thư thực quản giai đoạn III. 2) Nhận xét một số tác dụng không mong muốn của phương pháp này.

\section{II. ĐỐI TƯỢNG VÀ PHƯƠNG PHÁP NGHIÊN CỨU}

2.1. Đối tượng nghiên cứu: 42 bệnh nhân UTTQ giai đoạn III được HXTĐTTCsử dụng phác đồ $P C$ hàng tuần tại Bệnh viện Quân Y 103 và Bệnh viện Trung ướng Quân Đội 108 từ 2018 2020.

2.2. Phương pháp nghiên cứu: Nghiên cứu mô tả hồi cứu kết hợp tiến cứu.

Các bước tiến hành: - BN được khám lâm sàng và thực hiện các xét nghiệm trước điều trị.

- Sau khi BN được chẩn đoán UTTQ giai đoạn III theo phân loại TNM của hiệp hội ung thư Hoa Kì AJCC 8 năm 2017, tiến hành điều trị.

+ Hóa trị: Phác đồ PC hàng tuần (liêu Paclitaxel $50 \mathrm{mg} / \mathrm{m} 2$, Carboplatin AUC 2 pha truyền tĩnh mạch ngày 1 , chu kỳ 7 ngày trong quá trình xạ trị).
+ Xạ trị: kỹ thuật IMRT hoặc 3D - CRT (liều 50,4 Gy cho vùng thể tích dự phòng, $60-66$ Gy cho vùng $u$ và hạch nguyên phát).

- Đánh giá hiệu quả điều trị:

+ Đáp ứng trển cận lâm sàng: Dựa vào CLVT theo tiêu chuẩn RECIST.

+ Đánh giá mối liên quan của một sỗ yếu tố với hiệu quả điều trị.

+ Độc tính của HXTĐTTC: Dựa vào tiêu chuẩn đánh giá các biến cố bất lợi theo phiên bản 5.0 (Common Terminology Criteria for Adverse Events Version 5.0 - CTCAE) của Viện Ung thư quốc gia Hoa Kì năm 2009.

- Xử lý số liệu: Bằng phần mềm SPSS 25.0

\section{KẾT QUẢ NGHIÊN CỨU}

3.1. Đánh giá đáp ứng khách quan

Bảng 1. Đáp giá đáp ứng sau điều trị theo tiêu chuânn RECIST

\begin{tabular}{|c|c|c|}
\hline \multicolumn{3}{|c|}{ Đáp ứng } \\
\hline & $\begin{array}{c}\text { Số bệ̂nh nhân } \\
\text { (n= 42) }\end{array}$ & $\begin{array}{c}\text { Tỷ lệ } \\
(\mathbf{\%})\end{array}$ \\
\hline Đáp ứng & 36 & 85,7 \\
\hline Không đáp ứng & 6 & 14,3 \\
\hline Tống & 42 & 100 \\
\hline \multicolumn{3}{|c|}{ Cụ thế } \\
\hline Đáp ứng hoàn toàn & 14 & 33,3 \\
\hline Đáp ứng một phần & 22 & 52,4 \\
\hline Bệnh giữ nguyên & 6 & 14,3 \\
\hline Tiển triển & 0 & 0 \\
\hline Tống & 42 & 100 \\
\hline
\end{tabular}

Nhận xét: Tỷ lê đáp ứng hoàn toàn là $85,7 \%$ trong đó có $33,3 \%$ BN có đáp ứng hoàn toàn. Không có BN tiến triển sau điêuu trị.

\subsection{Một số yếu tố liên quan đến đáp ứng điêuu trị}

Bảng 2. Đáp ứng điều trị theo kích thước u

\begin{tabular}{|c|c|c|c|c|c|c|}
\hline \multirow{2}{*}{\multicolumn{3}{|c|}{ (2) }} & \multicolumn{2}{|c|}{ Có đáp ứng } & \multirow{2}{*}{$\begin{array}{l}\text { Không đáp ứng } \\
\text { Bệnh giữ nguyên }\end{array}$} & \multirow{2}{*}{ Tổng } \\
\hline & & & Hoàn toàn & Một phân & & \\
\hline \multirow{4}{*}{$\begin{array}{c}\text { Kích } \\
\text { thước u }\end{array}$} & \multirow{2}{*}{$<5 \mathrm{~cm}$} & $\mathbf{n}$ & 9 & 11 & 0 & 20 \\
\hline & & $\%$ & 45,0 & 55,0 & 0 & 100 \\
\hline & \multirow{2}{*}{$\geq 5 \mathrm{~cm}$} & $\mathbf{n}$ & 5 & 11 & 6 & 22 \\
\hline & & $\%$ & 22,7 & 50,0 & 27,3 & 100 \\
\hline \multirow{2}{*}{\multicolumn{2}{|c|}{ Tổng }} & $\mathbf{n}$ & 14 & 22 & 6 & 42 \\
\hline & & $\%$ & 33,3 & 52,4 & 14,3 & 100 \\
\hline \multicolumn{2}{|c|}{$\mathbf{p}=$} & \multicolumn{5}{|c|}{0,03} \\
\hline
\end{tabular}

Nhận xét: Khối u có kích thước $<5 \mathrm{~cm}$ có đáp ứng tốt hơn khối u có kích thước $\geq 5 \mathrm{~cm}$.Sự khác biệt có ý nghĩa thống kê với $\mathrm{p}<0,05$.

Bảng 3. Đáp ứng điều trị theo giai đoạn $T$

\begin{tabular}{|c|c|c|c|c|c|c|}
\hline \multicolumn{2}{|c|}{} & \multicolumn{2}{c|}{ Có đáp ứng } & \multicolumn{2}{c|}{ Không đáp ứng } & \multirow{2}{*}{ Tổng } \\
\cline { 3 - 7 } & & Hoàn toàn & Một phần & Bệnh giữ nguyên & \\
\hline \multirow{3}{*}{ Giai đoạn $\mathbf{T}$} & \multirow{2}{*}{$\mathbf{T}_{\mathbf{2}}$} & $\mathbf{n}$ & 5 & 1 & 0 & 6 \\
\cline { 3 - 7 } & \multirow{2}{*}{$\mathbf{T}_{\mathbf{3}}$} & $\mathbf{\%}$ & 83,3 & 16,7 & 0 & 100 \\
\cline { 3 - 7 } & & $\mathbf{0}$ & 9 & 21 & 6 & 36 \\
\hline
\end{tabular}




\begin{tabular}{|c|c|c|c|c|c|c|}
\hline \multirow{2}{*}{\multicolumn{2}{|c|}{ Tổng }} & $\mathrm{n}$ & 14 & 22 & 6 & 42 \\
\hline & & $\%$ & 33,3 & 52,4 & 14,3 & 100 \\
\hline \multicolumn{7}{|l|}{$\mathbf{p}$} \\
\hline \multirow{4}{*}{ Giaiđoạn N } & \multirow{2}{*}{$\mathbf{N}_{\mathbf{1}}$} & $\mathrm{n}$ & 12 & 12 & 0 & 24 \\
\hline & & $\%$ & 50,0 & 50,0 & 0 & 100 \\
\hline & \multirow{2}{*}{$\mathbf{N}_{\mathbf{2}}$} & $\mathbf{n}$ & 2 & 10 & 6 & 18 \\
\hline & & $\%$ & 11,1 & 55,6 & 33,3 & 100 \\
\hline \multirow{2}{*}{\multicolumn{2}{|c|}{ Tổng }} & $\mathbf{n}$ & 14 & 22 & 6 & 42 \\
\hline & & $\%$ & 33,3 & 52,4 & 14,3 & 100 \\
\hline \multicolumn{2}{|l|}{$\mathbf{p}=$} & \multicolumn{5}{|c|}{0,031} \\
\hline
\end{tabular}

Nhận xét: BN UTTQ giai đoạn $\mathrm{T}_{2}$ có đáp ứng với điều trị tốt hơn so với giai đoạn $\mathrm{T}_{3}$, giai đoạn $\mathrm{N}_{1}$ có đáp ứng tốt hơn giai đoạn $\mathrm{N}_{2}$. Sự khác biệt có ý nghĩa với $\mathrm{p}<0,05$.

Bảng 4. Đáp ứng điều trị theo kỹ thuật xạ trị

\begin{tabular}{|c|c|c|c|c|c|c|}
\hline \multirow{2}{*}{\multicolumn{3}{|c|}{ 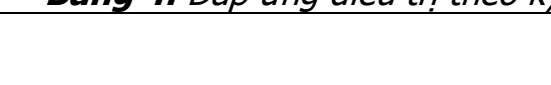 }} & \multicolumn{2}{|c|}{ Có đáp ứng } & \multirow{2}{*}{$\begin{array}{l}\text { Không đáp ứng } \\
\text { Bệnh giữ nguyên }\end{array}$} & \multirow{2}{*}{ Tổng } \\
\hline & & & Hoàn toàn & Môt phân & & \\
\hline \multirow{4}{*}{ Kỹ thuật xạ } & \multirow{2}{*}{ IMRT } & $\mathbf{n}$ & 12 & 18 & 1 & 31 \\
\hline & & $\%$ & 38,7 & 58,1 & 3,2 & 100 \\
\hline & \multirow{2}{*}{ 3D - CRT } & $\mathbf{n}$ & 2 & 4 & 5 & 11 \\
\hline & & $\%$ & 18,2 & 36,4 & 45,4 & 100 \\
\hline \multirow{2}{*}{\multicolumn{2}{|c|}{ Tổng }} & $\mathbf{n}$ & 14 & 22 & 6 & 42 \\
\hline & & $\%$ & 33,3 & 52,4 & 14,3 & 100 \\
\hline \multicolumn{2}{|c|}{$\mathbf{p}=$} & \multicolumn{5}{|c|}{0,006} \\
\hline
\end{tabular}

Nhân xét: BN được xạ trị bằng kỹ thuật IMRT có đáp ứng điều trị tốt hơn kỹ thuật 3D - CRT. Sự khác biệt có ý nghĩa thống kề $(p<0,05)$.

3.3. Tác dụng không mong muốn của phương pháp điêuu trị

Bảng 5. Tác dụng không mong muốn cấp tính do xạ trị

\begin{tabular}{|c|c|c|c|c|c|c|c|c|}
\hline \multirow{2}{*}{ Tác dụng phụ } & \multicolumn{2}{|c|}{ Không } & \multicolumn{2}{c|}{ Độ I } & \multicolumn{2}{c|}{ Độ II } & \multicolumn{2}{c|}{ Độ III-IV } \\
\cline { 2 - 9 } & Số lượng & $\mathbf{\%}$ & Số lượng & $\mathbf{\%}$ & Số lượng & $\mathbf{\%}$ & Số lượng & $\%$ \\
\hline Viêm da & 16 & 38,1 & 15 & 35,7 & 11 & 26,2 & 0 & 0 \\
\hline Viêm thực quản & 26 & 61,9 & 10 & 23,8 & 6 & 14,3 & 0 & 0 \\
\hline Viêm phối & 37 & 88,1 & 4 & 9,5 & 1 & 2,4 & 0 & 0 \\
\hline
\end{tabular}

Nhận xét: Các TDKMM do xạ trị hay gặp là viêm da $(61,9 \%)$, viêm thực quản $(38,1 \%)$ và viêm phổi $(11,9 \%)$. Tất cả ở mức độ 1 , độ 2 .

Bảng 6. Tác dụng không mong muốn cấp tính do hoá trị

\begin{tabular}{|c|c|c|c|}
\hline & \multirow[b]{2}{*}{$\begin{array}{c}\text { Số bệnh } \\
\text { nhẩn } \\
(n=42)\end{array}$} & \multirow[b]{2}{*}{$\begin{array}{l}\text { Tỷ lệ } \\
\text { \% }\end{array}$} \\
\hline & & & \\
\hline \multirow{3}{*}{ Buồn nôn } & Đô 0 & 36 & 85,7 \\
\hline & Độ 1 & 4 & 9,5 \\
\hline & Đố 2 & 2 & 4,8 \\
\hline \multirow{2}{*}{ Nôn } & Độ 0 & 40 & 95,2 \\
\hline & Đồ 1 & 2 & 4,8 \\
\hline \multirow{2}{*}{ Viêmmiệng } & Độ 0 & 40 & 95,2 \\
\hline & Độ 1 & 2 & 4,8 \\
\hline \multirow{2}{*}{ İa chảy } & Độ 0 & 39 & 92,9 \\
\hline & Độ 1 & 3 & 7,1 \\
\hline \multirow{2}{*}{ Rụng tóc } & Độ 0 & 39 & 92,9 \\
\hline & Độ 1 & 3 & 7,1 \\
\hline \multirow{2}{*}{$\begin{array}{l}\text { Độc tính trên } \\
\text { thần kinh (tê } \\
\text { bì chân tay) }\end{array}$} & Độ 0 & 38 & 90,5 \\
\hline & Độ 1 & 3 & 7,1 \\
\hline
\end{tabular}

Nhân xét: Các TDKMM do hoá trị hay gặp là buồn nôn $(14,3 \%)$; lả chảy, rụng tóc, tê bì chân

tay $(7,1 \%)$; nôn, viêm miệng $(4,8 \%)$. Tất cả ở độ 1 , độ 2 .

Bảng 7. Tác dung không mong muốn trên hệ huyêt học, gan thận

\begin{tabular}{|c|c|c|c|c|c|}
\hline \multirow[b]{2}{*}{$\begin{array}{c}\text { Tác } \\
\text { dụng } \\
\text { phụ }\end{array}$} & \multirow[b]{2}{*}{$\begin{array}{l}\text { Mức } \\
\text { độ }\end{array}$} & \multicolumn{2}{|c|}{ Trước điều trị } & \multicolumn{2}{|c|}{ Sau điêu trị } \\
\hline & & $\begin{array}{c}\text { Số } \\
\text { bệnh } \\
\text { nĥân } \\
(n= \\
42)\end{array}$ & $\begin{array}{l}\text { Tỷ lề } \\
(\%)\end{array}$ & $\begin{array}{c}\text { Số } \\
\text { bệnh } \\
\text { nhân } \\
(\mathrm{n}= \\
\mathbf{4 2})\end{array}$ & $\begin{array}{l}\text { Tỷ lệ } \\
\text { (\%) }\end{array}$ \\
\hline \multirow{3}{*}{$\begin{array}{l}\text { Giảm } \\
\text { huyết } \\
\text { sắc tố }\end{array}$} & Độ 0 & 41 & 97,6 & 28 & 66,6 \\
\hline & Độ 1 & 1 & 2,4 & 12 & 28,6 \\
\hline & Độ 2 & 0 & 0 & 5 & 11,9 \\
\hline \multirow{4}{*}{$\begin{array}{l}\text { Giảm } \\
\text { bạch cầu }\end{array}$} & Độ 0 & 41 & 97,6 & 24 & 57,1 \\
\hline & Độ 1 & 1 & 2,4 & 12 & 28,6 \\
\hline & Độ 2 & 0 & 0 & 5 & 11,9 \\
\hline & Độ 3 & 0 & 0 & 1 & 2,4 \\
\hline \multirow{4}{*}{$\begin{array}{l}\text { Giảm } \\
\text { bạch cầu } \\
\text { hạt }\end{array}$} & Độ 0 & 42 & 100 & 27 & 64,3 \\
\hline & Đồ 1 & 0 & 0 & 10 & 23,8 \\
\hline & Độ 2 & 0 & 0 & 4 & 9,5 \\
\hline & Đố 3 & 0 & 0 & 1 & 2,4 \\
\hline
\end{tabular}




\begin{tabular}{|c|c|c|c|c|c|}
\hline \multirow{3}{*}{$\begin{array}{l}\text { Giảm } \\
\text { tiểu câuu }\end{array}$} & Độ 0 & 42 & 100 & 33 & 78,6 \\
\hline & Đố 1 & 0 & 0 & 8 & 19,0 \\
\hline & Đố 2 & 0 & 0 & 1 & 2,4 \\
\hline \multirow{2}{*}{$\begin{array}{l}\text { Tăng } \\
\text { GOT }\end{array}$} & Độ 0 & 41 & 97,6 & 39 & 92,9 \\
\hline & Độ 1 & 1 & 2,4 & 3 & 7,1 \\
\hline Tăng & Độ 0 & 42 & 100 & 0 & 0 \\
\hline Creatinin & Đô̂ 1 & 0 & 0 & 42 & 100 \\
\hline \multicolumn{2}{|c|}{ Tống } & 42 & 100 & 42 & 100 \\
\hline
\end{tabular}

Nhận xét: Các tác dụng không mong muốn hay gặp trên hêe huyết học, gan, thận là giảm hemoglobine $(40,5 \%)$, giảm bạch cầu $(35,7 \%)$, giảm bạch cầu hạt $(35,7 \%)$, giảm tiểu cầu $(21,4 \%)$ có $7,1 \%$ BN tăng GOT và tăng creatinin sau điều trị. Hầu hết các TDKMM trên hệ huyết học, gan thận ở độ 1, 2; có 1 BN giảm bạch cầu và bạch cầu hạt mức độ 3 .

\section{BÀN LUÂN}

Sau HXTĐTTC, 90,5\% BN trong nghiên cứu của chúng tôi có đáp ứng về mặt lâm sàng, trong đó $40,5 \%$ BN có đáp ứng hoàn toàn, BN hết nuốt nghẹn, hết đau ngực, ăn uống tốt, tăng cân so với trước điều trị. Kết quả này cũng tương đương với kết quả của tác giả Dương Thuỳ Linh với tỷ lệ đáp ứng lâm sàng là 93,8\% [2].

Tỷ lệ đáp ứng trên hình ảnh chụp CLVT theo tiêu chuẩn RECIST 1.1 là $85,7 \%$, trong đó tỷ lệ đáp ứng hoàn toàn và đáp ứng một phần lần lượt là $33,3 \%$ và $52,4 \%$. Kết quả của chúng tôi cao hơn hẳn so với nghiên cứu sử dung xa trị đơn thuần của Hàn Thị Thanh Bình, khi tỷ lệ đáp ứng trong nghiên cứu này là $64,6 \%$ với $23,3 \%$ đáp ứng hoàn toàn [3]. Kết quả này cho thây Paclitaxel và Carboplatin truyền trước tia xạ đã làm tăng nhạy cảm của khối u đối với tia xạ. So với nghiên cứu của Nguyễn Đức Lợi, tỷ lệ bệnh nhân đáp ứng hoàn toàn là $84,9 \%$, trong đó có $29,5 \%$ đáp ứng hoàn toàn [4]. Điều này cho thấy lợi ích đáp ứng ban đầu của phác đồ HXTĐTTC với phác đồ $P C$ hàng tuần không kém hơn so với phác đồ $\mathrm{CF}$. Theo một số nghiên cứu nước ngoài, cũng cho thấy không có sự khác biệt về các tiêu chí đáp ứng khối u ban đầu, PFS và OS giữa nhóm BN hoá xạ trị với phác đồ $\mathrm{PC}$ hàng tuần so với phác đồ $\mathrm{CF}$. Như trong nghiên cứu của Honing J và cộng sự (cS) cho thấy không có sự khác biệt về đáp ứng điều trị, PFS và OS giữa 2 nhóm $(p>0,05)$ [5]. Trong điều trị bổ trợ và tân bổ trợ, theo Stefan Münch và cs cho thây không có sự khác biệt giữa 2 nhóm điều trị tân bổ trợ bằng hoá xạ trị đồng thời với phác đồ PC hàng tuần và $\mathrm{CF}[6]$.

Qua phân tích đơn biến cho thấy một số yếu tố liên quan đến đáp ứng điều trị bao gồm giai đoạn $T$ ( $T_{2}$ đáp ứng tốt hơn $T_{3}, p=0,023$ ), giai đoạn $\mathrm{N}$ ( $\mathrm{N}_{1}$ đáp ứng tốt hơn $\left.\mathrm{N}_{2}, \mathrm{p}=0,001\right)$, kích thước u (u kích thước nhỏ đáp ứng tốt hơn u có kích thước lớn, $p=0,033$ ), kỹ thuật xạ trị (xạ trị bằng kỹ thuật IMRT tốt hơn kỹ thuật $3 \mathrm{D}-\mathrm{CRT}$, $p=0,006)$. Các yếu tố không liên quan đến đáp ứng điêu trị bao gồm nhóm tuổi $(p=0,114)$ và vị trí u $(p=0,575)$. Các kết quả này cũng tương đồng với các nghiên cứu của Nguyễn Đức Lợi, Hàn Thị Thanh Bình, Kaneko và Kumakawa $Y$ [4], [3], [8], [9]. Theo tác giả Hàn Thị Thanh Bình, thời gian sống thêm trung bình của nhóm u có kích thước $<5 \mathrm{~cm}$ là 14 tháng, nhóm u có kích thước $\geq 5 \mathrm{~cm}$ là 4,6 tháng, sau 12 tháng không có bệnh nhân nào trong nhóm $u \geq 5 \mathrm{~cm}$ còn sống và tỷ lệ sống thêm 6 tháng cũng chỉ đạt 30\%, trong khi đó với nhóm u kích thước < $5 \mathrm{~cm}$ tỳ lệ sống thêm 6 tháng, 12 tháng, 18 tháng lần lượt là $72,7 \%, 37,5 \%$ và $25,6 \%(p<$ 0,001 ) [3]. Trong nghiên cứu của Nguyễn Đức Lợi, thời gian sống thêm toàn bộ trung bình của nhóm u có kích thước $\geq 5 \mathrm{~cm}$ là 19,5 tháng, trong khi đó nhóm u có kích thước $<5 \mathrm{~cm}$ là 29,7 tháng $(p=0,003)$ [4]. Theo nghiên cứu của Kaneko trên 57 bệnh nhân UTBM vảy thực quản giai đoạn $T_{3}, T_{4}$, cho thấy đáp ứng hoàn toàn giai đoạn $T_{3}, T_{4}$ lần lượt là $64 \%$ và $29 \%[7]$. Theo Ito và cộng sự, nghiên cứu 80 bệnh nhân UTTQ HXTĐTTC với 32 bệnh nhân xạ trị với kỹ thuật IMRT, 48 bệnh nhân xạ trị kỹ thuật 3D. Với kỹ thuật IMRT tỷ lệ sống 3 năm cao hơn so với kỹ thuật 3D, tỷ lệ lần lượt là $81,6 \%$ và $57,2 \%$, sự khác biệt có ý nghĩa thống kê với $p=0,037$ [8].

Hầu hết bệnh nhân có các chỉ số huyết học và sinh hoá (gan, thận) trong giới hạn bình thường. Có 1 bệnh nhân có thiếu máu độ 1 , chiếm 2,4\%; 1 bệnh nhân giảm bạch cầu độ 1 , chiếm $2,4 \%$ và 1 bệnh nhân có tăng men gan độ 1 , chiếm $2,4 \%$. Do vậy, những biến đổi về huyết học và sinh hoá (gan, thận) thể hiện rõ TDKMM mà các phương pháp ĐT mang lại. Các triệu chứng trên hệ huyết học chủ yếu ở độ 1 và 2 , chỉ có $2,4 \%$ BN giảm bạch cầu và bạch cầu NEUT đô 3. Các tác dụng phụ hay gặp như giảm bạch cầu $(42,9 \%)$, giảm bạch câu NEUT $(35,7 \%)$, giảm Hemoglobin $(33,4 \%)$, giảm tiểu câu $(21,4 \%)$, tăng men gan $(7,1 \%)$ và không có BN tăng Creatinin. Các TDKMM ngoài hệ huyết học bao gồm buồn nôn $(14,3 \%)$, nôn $(4,8 \%)$, viêm miệng $(4,8 \%)$, ỉa chảy $(7,1 \%)$, rụng tóc và tê bì tay chân đều là $7,1 \%$.Đa phần các triệu chứng trên đều ở mức độ 1 , không ảnh hưởng đến quá trình điều trị và bệnh nhân thường hồi phục sớm với các điều trị kết hợp. Các nghiên cứu trên thế giới cũng cho thấy BN được HXTĐT 
với phác đồ $\mathrm{PC}$ hàng tuần có tỷ lệ mắc TDKMM sau điều trị thấp hơn, đặc biệt là tỷ lệ TDKMM độ 3,4 thấp hơn so với dùng phác đồ CF [5], [6].

Các TDKMM do tia xạ hay gặp trong nghiên cứu của chúng tôi bao gồm viêm da $(61,9 \%)$, viêm thực quản $(38,1 \%)$ và viêm phổi $(11,9 \%)$. Kết quả này thấp hơn so với nghiên cứu của Nguyến Đức Lợi và Hàn Thị Thanh Bình [4], [3]. Có thể do đa phần $\mathrm{BN}$ trong nghiên cứu của chúng tôi được xạ trị theo kỹ thuật IMRT, do vậy tác dụng phụ trên da và thực quản cũng ít hơn. Tỷ lệ viêm thực quản thấp hơn so với nghiên cứu của Zhao với tỷ lệ viêm độ 1 , độ 2 tương ứng là $25 \%$ và $46,4 \%$, có thể do Zhao sử dụng phương pháp đa phân liêu $1,5 \mathrm{~Gy}$ x 2 lần/ngày, do đó mà liêu tia trong ngày cao hơn so với các phương pháp khác.

\section{KẾT LUÂ̂N}

HXTĐTTC với phác đồ hoá chất PC hàng tuần điều trị bệnh nhân UTTQ giai đoạn III có tỷ lệ đáp ứng lâm sàng là $90,5 \%$, đáp ứng theo tiêu chuẩn RECIST 1.1 là $90,5 \%$ với $33,3 \%$ BN đáp ứng hoàn toàn. Do vậy, phương pháp ĐT này đảm bảo tốt kế hoạch điều trị, TDKMM chấp nhận được và hiệu quả điều trị tương đương khi sử dụng phác đồ CF. Vì vậy có thể ưu tiên lựa chọn trong hoá xạ trị đồng thời cho bệnh nhân.

\section{TÀI LIÊU THAM KHẢO}

1. Bray F., Ferlay J., Soerjomataram I., et al
(2020), "Globocan 2020: Estimated Cancer Incidence, Mortality and Prevalence Worldwide in for 36 cancers in 185 countries", CA Cancer J Clin.

2. NCCN (2020), "Esophageal cancer", Clinical Practice Guidelines in Oncology.

3. Hàn Thị Thanh Bình (2004), "Nhận xét đặc điểm lâm sàng, mô bệnh học và kết quả điều trị ung thư biểu mô thực quản tại Bệnh viện $K$ giai đoạn 1998 - 2004", Luận văn tốt nghiệp bác sĩ nội trú, Đại học Y Hà Nội.

4. Nguyê̂n Đức Lợi (2015), "Đánh giá hiệu quả phác đồ hoá xạ trị đồng thời và một số yếu tố tiên lượng ung thư biểu mô thức quản giai đoạn III, IV tại bệnh viện $\mathrm{K}^{\prime \prime}$, Luận án tiển sî y học, Đại học Y HN.

5. Horning J., Śmit J. K., Muijs C. T., et al. (2014), "A comparison of Carboplatin and Paclitaxel with Cisplatinum and 5-Fluorouracil in definitive chemoradiation in esophageal cancer patients",Ann Oncol, 25(3), pp.638.

6. Münch S., Pigorsch S. U., Feith M., et al. (2017), "Comparison of neoadjuvant chemoradiation with carbolatin/paclitaxel or cisplatin/5-Fluoruracil in patients with squamous cell carcinoma of the esophagus, Radiant Oncol LondEngl, pp.12.

7. Kaneko K., Ito H., Konishi K., et al.(2003), "Definitive chemoradiotherapy for patients with malignant stricture due to T3 or T4 squamous cell carcinoma of the oesophagus", Br J Cancer, 88(1), pp.18-24.

8. Ito M., Kodaira T., Tachibama H., et al.(2017), "Clinical results of definitive chemoradiotherapy for cervical esophageal cancer: Comparison of failure pattern and toxicities between intensity modulated radiotherapy and 3 - dimensional conformal radiotherapy", Head neck, 39 (12): pp.2406-2415.

\section{NGHIÊN CỨU ĐĂC ĐIỂM HÌNH ẢNH BỆNH LÝ DỊ DẠNG MẠCH MÁU NGOẠI BIỀN}

\section{TÓM TẮT}

Mục tiêu: Mô tả đặc điểm hình ảnh dị dạng mạch máu ngoại biên. Phướng pháp: Tiến cứu hàng loạt ca bệnh, có can thiệp không nhóm chứng các bệnh nhân có chẩn đoán dị dạng mạch máu ngoại biên từ tháng 06/2016 đến tháng 03/2019 tại bênh viện Nhân dân Gia Định, đáp ứng đủ các tiêu chuẩn lựa chọn và loại trừ theo mẩu bệnh án nghiên cứu. Tất cả các bệnh nhân được trải qua các bước khám lâm sàng, hình ảnh học. Chẩn đoán dị dạng mạch máu ngoại

\footnotetext{
*Đai hoc Y khoa Phạm Ngoc Thạch

**Bệnh viện Nhân dân Gia Định

Chịu trách nhiệm chính: Nguyễn Đình Luân

Email: drluannguyen@yahoo.com

Ngày nhận bài: 8/3/2021

Ngày phản biện khoa học: 2/4/2021

Ngày duyệt bài: 3/5/2021
}

\section{Đặng Vĩnh Hiệp*, Nguyễn Đình Luân**}

biên dựa vào phân loại của ISSVA 2014. Kết quả: Có 103 BN thoả điều kiện nghiên cứu, trong đó có 35 nam (34\%) và 68 nữ (66\%). Tuối trung bình của nhóm nghiên cứu là 24,2 $\pm 14,1$, trong đó chủ yếu là nhóm > 18 tuổi $(55,3 \%)$. Chấn đoán dị dạng mạch máu theo phân loại ISSVA 2014 thì có $72,8 \%$ là dị dạng tĩnh mạch (VM), 15,5\% dị dạng động tĩnh mạch (ẢVM), còn lại là các di dạng mạch máu khác. Khổng có sự khác biệt về tuối, giới đối với các loại dị dạng mạch máu. Siểu âm có giá trị chẩn đoán tốt nhất đổi với dị dạng bach mạch $(66,7 \%)$. CLVT chẩn đoán di dang động tĩnh mach trong $100 \%$ các trường hợp. Đối với các dị dạng dòng chậm, $\mathrm{CHT}$ chẩn đoán chính xác $100 \%$ các trường hợp. Tiuy nhiên với các di dang lưu lượng cao, giá trị chẩn đoán của $\mathrm{CHT}$ chì là $46,7 \%$. Kểt luân: Siêu âm là phương tiện đâu tay trong chẩn đoán dị dạng mạch máu. CLVTं và CHT giúp chẩn đoán chính xác, mức độ lan rộng và tương quan với các cấu trúc xung quanh, theo dõi sau điều trị. 